\title{
New evidence for a volcanically, tectonically, and climatically active Mars
}

\author{
Álvaro Márquez , Carlos Fernández , Francisco Anguita , Agustín Farelo , \\ Jorge Anguita , Miguel-Ángel de la Casa
}

\begin{abstract}
Geological analysis of Mars imagery supports the hypothesis that the planet has been the site of recent $(<10 \mathrm{Ma})$ volcanic and tectonic processes and glacier flow, and makes most likely previous sugges ons of continuing endogenic and exogenic activity. Tectonic stuctures which defonn very slightly cratered (at MOC scales) surfaces of Tharsis Montes and surrounding regions seem to attest to active tectonism (both extensional and wanscurrent) on Mars. Exogenic processes in this region. such as a glacial origin for the aureole deposits on the northwestern flanks of the Tharsis Montes shield volcanoes, are supported by new data. The very recent age of these stuctures could be the first direct confimation that changes in obliquity are modulating the marian climate, such that an increase in obliquity would result in equatorial glaciers taking the place of the receding polar ice caps. If this and other concurring research is extended and confinned, the 'alive Mars' which would emerge would constitute a most appealing place for exobiology and comparative planetology.
\end{abstract}

Keywords: Mars; Tectonics; Volcanism; Gobal climate change

\section{Introduction}

Three decades of robotic exploration of Mars have been inconclusive on several major problems: the existence of life (e.g., McKay, 1986), the past and present inventory of water (Carr, 1996; Baker, 2001), and the amount of residual intemal energy in the planet (Hartmann et al., 1999; Anderson and Dolım, 2000; Harmann and Berman, 2000; Garvin et al., 2000; Jakosky and Phillips, 2001; Anguita et al., 2001; Solomon et al., 2002; Burr and McEwen, 2002; Dohm et al., 2002; Frey, 2003). These questions are evidently related, since life (as we know it, so we use to say) requires water and a source of energy. Of no lesser importance is the chronological aspect of the problem: to search for microfossils $4 \mathrm{Ga}$ old is a very different endeavor when compared to the quest for present livable habitats. In what follows we report information which places a very short upper time limit on three types of activity (meteorologic, tectonic, and volcanic) central to the water and energy problems; and consequently to the life-on-Mars question.

\section{Volcanics and glaciers of the aureole deposits of Tharsis Montes}

We have selected for this study volcanic and sedimentary formations disrupted by regional faults in a young area. The aureoles on the northwestem flanks of the three Tharsis Montes shield volcanoes (Fig. 1) are complex fan-shaped deposits adding together $\sim 2 \times 10^{5} \mathrm{~km}^{2}$, which drape the volcanoes' northwestern slopes. They consist of three types of terrain (Zimbehnan and Edgett, 1992; Anguita and Moreno, 


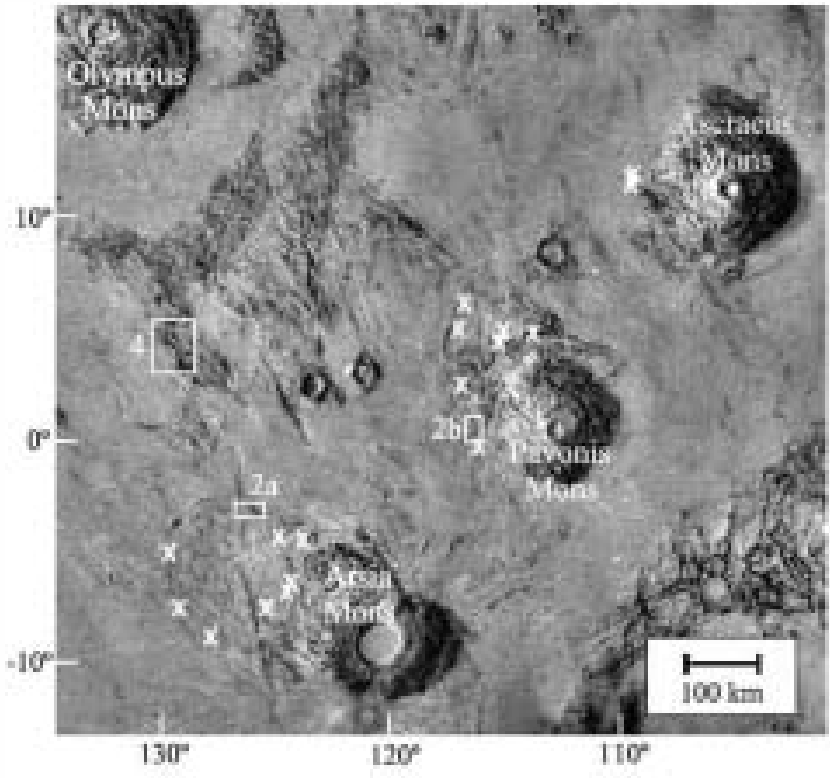

Fig. 1. The Tharsis Montes and their surrounding area Rectangles mark the position of Figs. 2a, 2b, and 4; crosses, the location of images where crater counts have been carried out.

1992; Scott and Zimbehnan, 1995; Scott et al., 1998; Head and Marchant, 2003): knobby (which makes the core of the fans), ridged (an outer envelope tens of $\mathrm{km}$ wide, with parallel closely spaced crests), and lobated. Their origin has been disputed, but presently a majority of specialists (Williams, 1978; Lucchitta, 1981; Anguita and Moreno, 1992; Hodges and Moore, 1994; Helgason, 1999; Head and Marchant, 2003) favor the glacier hypothesis against a volcanic sectorcollapse. Head and Marchant (2003), for instance, interpret the ridged terrain as drop moraines, the knobby terrain as sublimation tills, and the lobated terrain as rock glaciers, some of which may still be active. The authors of the USGS geologic maps of the area (Scott and Zimbehnan, 1995; Scott et al., 1998) explain the lobated terrain as a volcanic explosive formation, but they agree with a glacier origin for the ridged and knobby terrain, which account for ahnost $90 \%$ of the aureoles deposits.

The aureole deposits of Arsia and Pavonis are cut by long sigmoid fractures. Based on stratigraphic and crosscutting relations, as well as a lack of superposed craters, the faults in Fig. 2 (that are not radial to the volcanic constructs) appear to have served as volcanic conduits during a late-stage magmatic activity of Tharsis. The altitude of these vents (respectively 7500 and $4000 \mathrm{~m}$ lower than the Arsia and Pavonis caldera floors) probably indicates that their hydrostatic heads were insufficient to raise the magma up to the edifice summits. The flow escarpment, in excess of $300 \mathrm{~m}$ high as measured on MOLA topography (Fig. 2c), indicates a high viscosity lava. The flows issuing from the faults show two essential stratigraphic relations: first, they overlie the knobby terrain; and second, they have in tum been fractured after their emplacement. From these observations we deduce the following sequence of events (from
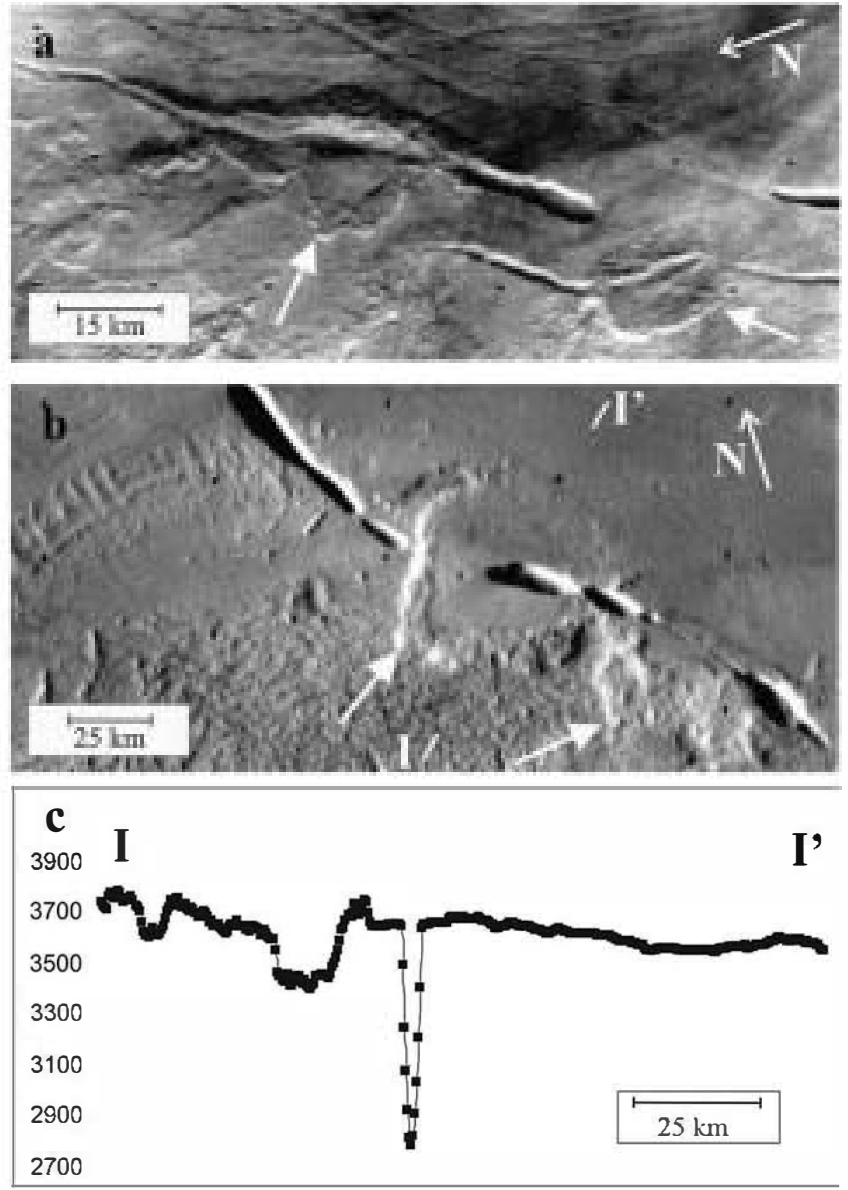

Fig. 2. (a) Volcanic outpourings (arrows) from faults in Pavonis' aureole (Viking Orbiter image 049B36). Note that in both cases the flows come out from left twists in the faults, a feature suggesting a ranstensional stress field. (b) Two thick flows (arrows) issuing from a farlt at the northem end of Arsia Mons' aureole (Viking Orbiter image 043B44); the elevation profile of (c) is signaled. (c) MOLA profile across the flow of (b) Though its northem end is almost masked by another Arsia flows, it stands clearly as a unit issued from the fault and overlying the Arsia aureole.

oldest to youngest): mountain glaciers flow from the Tharsis volcanoes, leaving an apron of moraines when they wane; Tharsis-induced tectonism results in the reactivation or formation of megafractures that cut lava flows and moraine deposits; lavas emplaced from a fissure-fed flank eruption (possibly unchained by the fracture itself, as suggested by Dohm et al., 2001a, 2001b) cover the glacier deposits; and finally, the faults slip again, disrupting the late volcanics. This scenario is generally supported by the observations of Scott and Zimbehnan (1995), and Head and Marchant (2003), who contend that most of the aureole deposits are contemporaneous with the latter stages of Arsia Mons volcanism.

The aureole deposits of Tharsis Montes shield volcanoes have been formed recently, as evidenced by the paucity of impact craters at typical Viking images resolution. Mars Orbital Camera images show a small number of craters, which we have counted on 16 images. We counted only those impact craters that displayed distinct rims, since those with highly degraded morphologies indicate aureole modifica- 
tion. The results are shown in Fig. 3 and Table 1, where the counts have been compared with lunar maria craterization data. Only the middle-sized craters are useful for age determinations, since many of the smaller ones $(\leqslant 16 \mathrm{~m})$ are prone to have been eroded or otherwise obliterated, and the bigger ones $(\geqslant 128 \mathrm{~m})$ are too scarce to be statistically reliable. Taking this into account, our best estimates are lunar maria ages of $(1.0 \pm 0.5) \times 10^{-3}$ for Arsia Mons aureole deposits, and slightly lower rates, $(2.0 \pm 0.4) \times 10^{-4}$ and $(2.1 \pm 1.1) \times 10^{-4}$, for Pavonis and Ascraeus Montes aureole deposits respectively. Two of the four crater bins with less statistical dispersion show no age differences among the

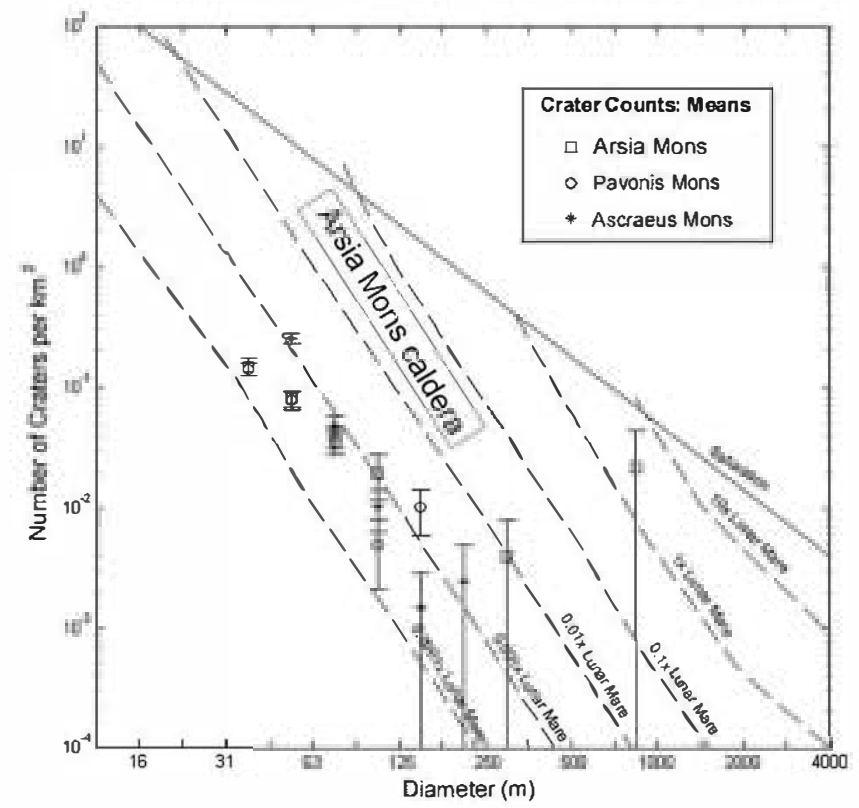

Fig. 3. Crater counts from $18 \mathrm{MOC}$ images of the Tharsis Montes' aureoles (locations in Fig. 1). Most of the counts project between the curves of 0.001 and 0.0001 the lunar maria cratering rate (see discussion in the text). Sign "Arsia Mons Caldera" refers to the data of Harmann et al. (1999), also discussed in the text. three aureoles, while Ascraeus Mons deposits appear older for the craters in the $50 \mathrm{~m}$-class, and Arsia Mons deposits appear older in the $100 \mathrm{~m}$-class. Our tentative interpretation of the crater retention ages is that the Tharsis Montes aureole deposits are coeval within the limits of this dating technique. The usually accepted Mars/Moon cratering ratio (Harmann et al., 2001) of 0.9-1.6 permitted Harmann et al. (1999) to give a maximum age of 40 to $100 \mathrm{Ma}$ for the Arsia Mons caldera floor, which we have also projected on our graph. The difference of ahnost two orders of magnitude between the two sets of counts (both performed with the same criteria) allows us to suggest ages younger than $10 \mathrm{myr}$ for the three aureoles, thereby giving a maximum relative age not only for the glacier advance, but also for the tectonic and volcanic activity on this area. This conclusion is in line with the recent work of many authors (Harmann et al., 1999; Garvin et al., 2000; Harmann and Berman, 2000; Dohm et al., 2001a, 2001b; Jakosky and Phillips, 2001; Burr and McEwen, 2002) who have found evidence for recent and even possibly active volcanism not only at Tharsis, but also at Elysium and the northern plains as well.

\section{The rifts northwest of Arsia Mons}

Working with Viking Orbiter images, Anguita et al. (2001) proposed the presence at Tharsis (and especially at Thaumasia Plateau, the southem block of the dome) of compressive, strike-slip, and extensional faults not explained by vertical tectonics. Other recent efforts concur with those observations, highlighting the Thaumasia highlands (southern margin of the Thaumasia plateau) as an ancient mountain range that may have resulted from plate tectonism early in Mars history (Middle Noachian; e.g., see Baker et al., 2002). Similar activity is noted elsewhere for the same time period (Fairén et al., 2002). We are presently using MOC images to confirm the preliminary hypothesis of Anguita et

Table 1

Crater counting data on $16 \mathrm{MOC}$ images of Tharsis volcanoes aureoles

\begin{tabular}{|c|c|c|c|c|c|c|c|}
\hline $\begin{array}{l}\text { hnage } \\
\text { (MOC) }\end{array}$ & $\begin{array}{l}\text { Scale } \\
\text { (mpixel) }\end{array}$ & $\begin{array}{l}\text { Latitude } \\
(\bullet)\end{array}$ & $\begin{array}{l}\text { Longitude } \\
\left({ }^{\circ}\right)\end{array}$ & $\begin{array}{l}\text { Surface } \\
\text { (pixels) }\end{array}$ & $\begin{array}{l}n>44 \mathrm{~m} \\
\left(\text { per } 10^{3} \mathrm{~km}\right)\end{array}$ & $\begin{array}{l}n>88 \mathrm{~m} \\
\left(\text { per } 10^{3} \mathrm{~km}\right)\end{array}$ & $\begin{array}{l}n>177 \mathrm{~m} \\
\left(\text { per } 10^{3} \mathrm{~km}\right)\end{array}$ \\
\hline e1003061 & 5.95 & -10.16 & 124.92 & $11392 \times 512$ & 116.24 & 24.24 & 4.84 \\
\hline $\mathrm{m} 0002826$ & 3.48 & -9.64 & 127.33 & $4864 \times 768$ & 197.80 & 44 & 22 \\
\hline $\mathrm{m} 0002942$ & 8.74 & -6.73 & 123.47 & $6144 \times 336$ & 101.40 & 0 & 0 \\
\hline $\mathrm{m0} 02724$ & 3.49 & -5.05 & 127.86 & $4480 \times 1024$ & 196.90 & 17.90 & 0 \\
\hline $\mathrm{m} 1000845$ & 1.46 & -6.98 & 128.12 & $1792 \times 2048$ & 406 & 0 & 0 \\
\hline $\mathrm{m} 1801134$ & 2.92 & -7.18 & 128.41 & $2816 \times 1024$ & 162.60 & 0 & 0 \\
\hline e0500055 & 5.96 & 12.46 & 108.16 & $5632 \times 512$ & 68.30 & 0 & 0 \\
\hline $\mathrm{m} 0202580$ & 5.90 & 11.66 & 109.34 & $5632 \times 1254$ & 228.90 & 0 & 0 \\
\hline $\mathrm{m} 0702694$ & 5.90 & 11.86 & 109.01 & $17024 \times 512$ & 407.14 & 18.24 & 0 \\
\hline m0804401 & 6.55 & 11.82 & 108.71 & $21120 \times 512$ & 133.71 & 9.91 & 2.48 \\
\hline e1000231 & 5.94 & 2.28 & 116.08 & $24448 \times 512$ & 119.98 & 13.58 & 0 \\
\hline e1002898 & 3.61 & 4.68 & 114.45 & $6016 \times 1024$ & 74.80 & 12.50 & 0 \\
\hline $\mathrm{m0302024}$ & 3.52 & 5.70 & 117.44 & $4864 \times 768$ & 171.60 & 0 & 0 \\
\hline $\mathrm{m} 0703326$ & 3.52 & 4.26 & 115.79 & $4480 \times 1024$ & 88 & 17.60 & 0 \\
\hline $\mathrm{m} 0902436$ & 2.94 & 3.35 & 116.84 & $4864 \times 512$ & 185.50 & 46.50 & 0 \\
\hline $\mathrm{m0} 04477$ & 1.46 & 5.66 & 116.15 & $1536 \times 3103$ & 0 & 0 & 0 \\
\hline
\end{tabular}



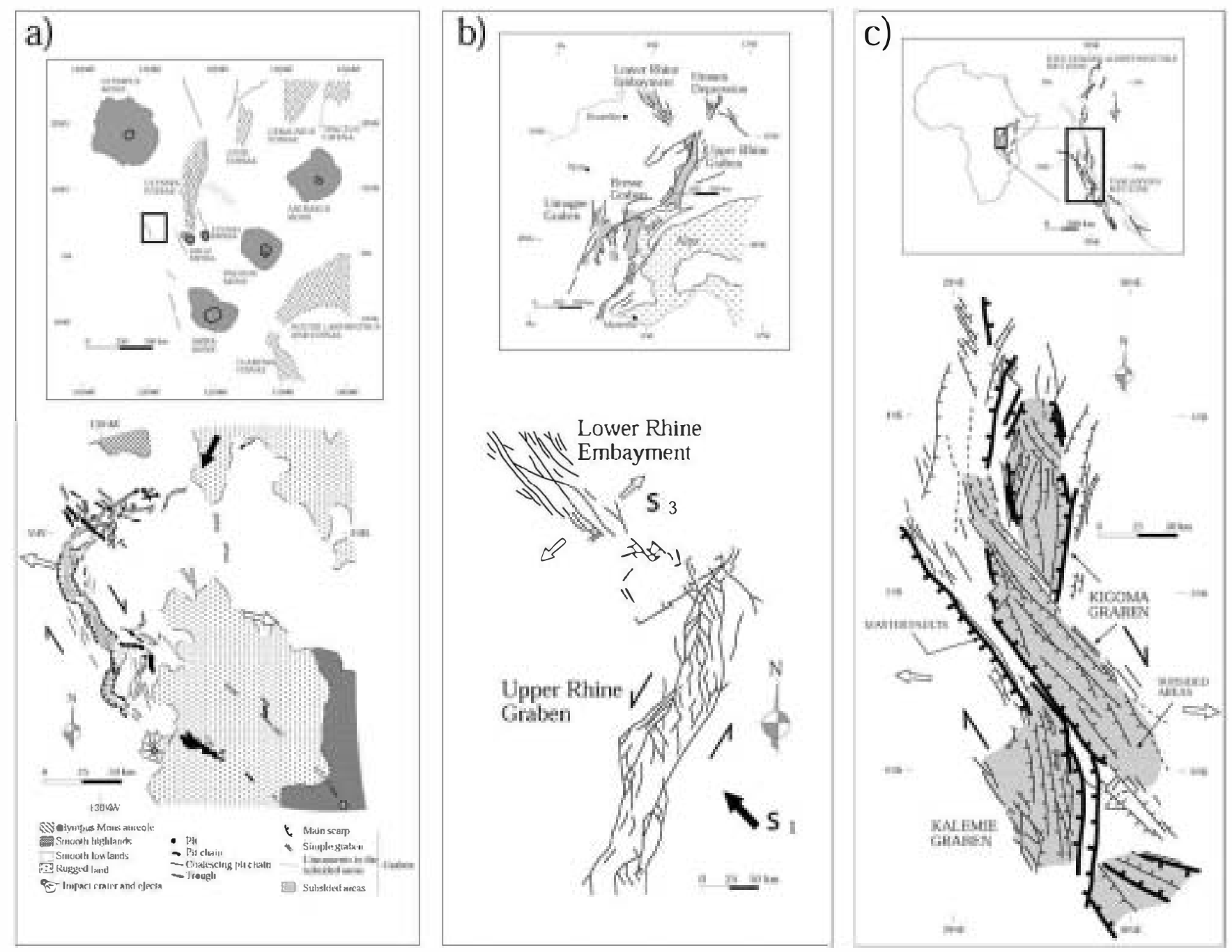

Fig. 4. (a) Geomorphic and stnuctural sketch of the $4^{\bullet} \mathrm{N}, 130^{\bullet} \mathrm{W}$ graben. The white arrows show the inferred extension direction, normal to the dechuced horizontal shortening (black amrow). (b) Structural map of the Rhine Graben aocording to Brun et al. (1992). The black arrow indicates the Neogene compression direction. (c) Sinicture of the Kigoma and Kalemie graben, in the Tanganyika Lake Rift Zone, modified after Rosendahl (1987). White anrows as in (a) and (b).

al. (2001). Following along $300 \mathrm{~km}$ to the northwest the azimuth of the fault of Fig. $2 b$, an unnamed, arcuate graben (centered at $4^{\bullet} \mathrm{N}, 130^{\circ} \mathrm{W}$ ) 170 -km long with the same general trend (see Fig. 1) is found. Both the fault and the graben are an extension of the Claritas Fossae group, relative agedated (Anderson et al., 2001) as Middle-Late Amazonian. Geomorphic and structural analyses using MOC imagery (M00-02329) of the bottom of this graben (Fig. 4a), indicate that its main branch, $120-\mathrm{km}$ long and $12-\mathrm{km}$ wide, is bound by two large, arcuate, en echélon-arranged scarps.

The most visible landforms of the subsided area of the graben (Fig. 5) are ridges and grooves of supposed eolian origin, which parallel the long axis of the depression. The ridges are systematically asymmetric, with their eastern faces steeper than the westem ones. Layering, frequently dipping westward, can be clearly seen on these east-facing cliffs (arrows on Fig. 5b), interpreted here as a series of cuestas. In other cases, the bedding is horizontal and defines large tabular plateaux. A summary of these observations is plotted on Fig. 5c. Cuestas and plateaux are laterally discontinuous, abutting against thin linear, roughly E-W-directed features, which we interpret as vertical fractures. These discontinuities divide the MOC-covered area into three domains (blocks A, B, and C, Fig. 5a), similar to the transversal division of the Rhine (Fig. 4b) and Tanganyika (Fig. 4c) graben by transfer faults. As for the northern and southern ends of the main graben, their structures are diverse: on the north they form an orthogonal pattem of minor graben and coalescing pit chains, while on the south we see a bifurcation of considerable structural complexity, with en echélon minor graben that cut a rugged terrain.

As can be seen in Fig. 5d, we interpret the westward dip of the layers in the area which contains the cuestas as the surface expression of a half-graben. In absence of any evidence of faults parallel to the strike, folding (some examples of which can be seen (Fig. 5c, arrowed) at the southern part of block A) may best explain the transition from tilted to horizontal layers. These folds would repre- 


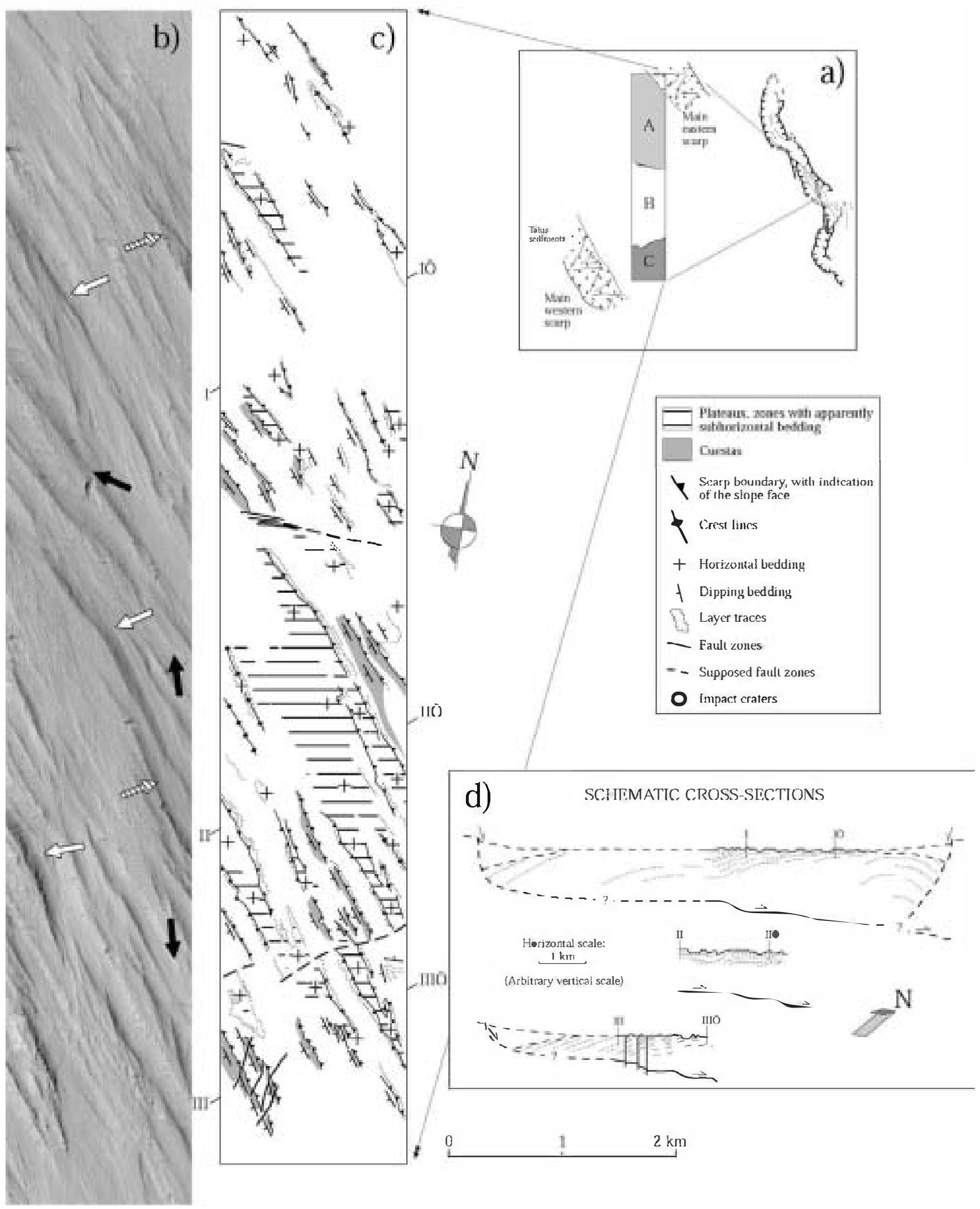

Fig. 5. (a) The position of the M०C image M00-0232 on a sketch of the $4^{\bullet} \mathrm{N}, 130^{\bullet} \mathrm{W}$ graben. The sectors A, B, and C are explained in the text. (b) The M○C image M00-02329. Black anrows point to folds; white ones, to west-dipping layers; and striped ones, to possible impact craters. (c) Geomorphic and structural interpretation. (d) Schematic cross-sections. 


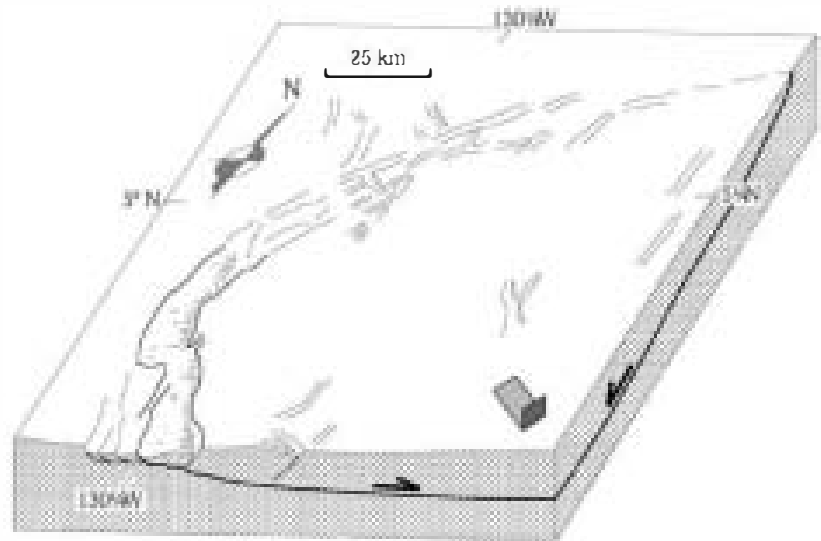

Fig. 6. Block diagram showing the stnuctural interpretation of the northern half of the $4^{\bullet} \mathrm{N}, 130^{\bullet} \mathrm{W}$ graben. Arbitrary vertical scale

sent accommodation structures associated to irregularities or steps of the basal detachment. The western, eastwarddipping scarp of the graben would be the detachment breakaway, while the eastem scarp marks a high-angle antithetic normal fault (cross-section I-I', Fig. 5d). This interpretation of the eastward-dipping master detachment is coherent (see, e.g., Rosendahl, 1987) with the east-facing large-scale arcuate pattem. A three-dimensional, schematic diagram of the regional structure (Fig. 6), portrays a large detachment fault resulting from asymmetric extensional tectonism (e.g., Wemicke and Burchfiel, 1982). The strike-slip component of the displacement could be a mere consequence of the activity of the transfer faults, though a regional cause cannot be discarded.

Comparison of this graben with graben of the Rhine or Tanganyika is supported by their structural and size similarities. The arcuate and oblique faults, en-echélon arrangement of structures, and overall asymmetry, are common features of all the three cases (e.g., Rosendahl, 1987; Prodehl et al., 1995). The profound difference may be that while the structural architectures of the Earth examples are customarily based on a plate tectonics framework, this is commonly denied for Mars (and specifically for modern Mars). Our structural analysis is completed with the observation that only two (suspect) impact craters ( 125 and $80 \mathrm{~m}$ across) have been located on all the $16 \mathrm{~km}^{2}$ of the MOC image. The extensive, conspicuous layering means that the dust cover is scarce, and thus that the probability that many craters are concealed by dust is exceedingly small. In accordance with the results based on our geological assessment and crater counting of the aureole deposits of Thars is Montes, we interpret that the graben centered at $4^{\bullet} \mathrm{N}, 130^{\circ} \mathrm{W}$ is a recent, possibly active tectonic structure caused by a compression with a NNE-SSW azimuth.

\section{Equatorial and polar glaciers on Mars}

The recent age of the aureole deposits of Thars is Montes deduced from the crater counts concurs with the presence of young glacier deposits on the flanks of the Tharsis Montes shield volcanoes. This in tum means very recent climatic conditions sharply contrasting with those existing at the present at this high altitude (surface pressure around $3 \mathrm{mbar}$ and maximum temperatures below $200 \mathrm{~K}$ (Carr, 1996)). In this climatic regime, ice would immediately sublimate because of the very low air moisture. The present water content of the martian amosphere is about $10 \mathrm{pr} \mu \mathrm{m}$. The large ice masses needed to deposit the moraines clearly require a denser atmosphere with a significantly larger content of water, capable to sustain a steady precipitation regime. Moreover, this atmosphere would have to be stable during significant periods of time, since the mantling of $200,000 \mathrm{~km}^{2}$ by cold-based glaciers (Head and Marchant, 2003) is a very slow process requiring a continuous ice supply. Furthermore (after Colaprete and Jakosky, 1998), temperatures above $220 \mathrm{~K}$, neatly higher than those existing today at this high altitude, are essential for ice to flow.

The only proposed mechanisms capable to generate a recent, denser atmosphere, which in tum would allow higher moisture and temperatures, are (1) MEG AOUTFLO events (Baker et al., 1991, 2000; Baker, 2001), where volcanoes would periodically recharge the martian atmosphere with greenhouse gases; and (2) a sharp variation in the martian orbital parameters (Laskar, 1989, 1990; Kieffer and Zent, 1992; Touma and Wisdom, 1993; Laskar and Robutel, 1993; Mustard et al., 2001; Jakosky and Phillips, 2001; Costard et al., 2002; Laskar et al., 2002). Two different variations are hypothesised for this orbital climate forcing: One with a short period ( $\sim n \vee 10^{5} \mathrm{yr}$ ), and another, which can be extrapolated from the present orbital conditions and begins to diverge rapidly from them 4 or $5 \mathrm{Ma}$ backwards (reaching, for instance, $40^{\circ}$ at $4.5 \mathrm{Ma}$, Touma and Wisdom, 1993; and $47^{\bullet}$ at 8 to $9 \mathrm{Ma}$, Laskar et al., 2002). It is interesting to note that this abrupt obliquity transition, already emphasized by Ward and Rudy (1991) seems independent of the initial proposed conditions.

Obliquities of $35^{\circ}$ or larger would cause the sublimation of great amounts of $\mathrm{CO}_{2}$ - and water-ice from the polar deposits, giving rise to atmospheric pressures above $25 \mathrm{mbar}$, and an atmospheric water content at the equator between 500 and 1000 pr $\mu \mathrm{m}$ (Mischna et al., 2003). Given these meteorological conditions, precipitation would follow; moreover, the saturation temperature of the martian atmosphere for this proposed water content would be around $230 \mathrm{~K}$ (Mellon and Jakosky, 1993), which means that the precipitated ice-forming snow could flow as glaciers. Amospheric simulations using the NASA Ames Mars Global Circulation Model show (Haberle et al., 2000) that in these high obliquity conditions significant quantities of ice would preferently accumulate in several martian non-polar zones. The high elevations in the Tharsis area are among the regions favored for repetitive snowfall and ice accumulation (Haberle et al., 2000; Cabrol and Grin, 2001). The presence of moraines on all three Tharsis Montes shield volcanoes seems therefore to indicate a link between topography and glacier formation. 
An interesting point is that the aureoles are located at the northwestem side of the volcanoes, which is the leeward flank. In principle, this is puzzling since relief-conditioned precipitations would be expected windward of the volcanoes. Leovy (2001) nevertheless states that the martian lowlatitude surface winds probably blow preferentially on the eastern side of huge topographic barriers, such as the Tharsis volcanic constructs. It thus appears, as previously advanced by Hodges and Moore (1979), that the location of glaciers in the wind-protected flanks is related to the preferent preservation of ice from wind ablation there. In addition, as mountain glaciers on Tharsis volcanoes seem to be developed during recent periods of high obliquity (see Discussion), the key factor to understand why glaciers are located just on western slopes it is not the present wind regime, but the wind regime at high-obliquity times. GCM simulations by Haberle et al. (2003) show, however, that the only significant change in the general atmospheric circulation at low latitudes seems to be an increase of the westerly low-level jet, which would enhance the "barrier" effect of the Tharsis volcanoes over their western flanks.

\section{Discussion}

Although Weiss et al. (2002) reached the conclusion that martian surface temperatures perhaps have not changed substantially in the last $4 \mathrm{Ga}$, a wealth of diverse data seem to point to the contrary: gullies apparently formed by liquid water (e.g., Gihnore and Phillips (2002), though a dry mechanism has been proposed for their origin (Treiman, 2003)), recent aqueous floods (Burr and McEwen, 2002) and sediments (Baker, 2001), the abrupt recession (Fishbaugh et al., 2000; Mustard et al., 2001) and present rapid sublimation of the ice in the southem polar cap (Malin et al., 2001), as well as the apparent short accumulation history of the Polar Layered Deposits of the northern cap (Byrne and Murray, 2002; Laskar et al., 2002). This body of evidence indicates an unstable martian surface environment in the recent past and probably even today. The analyses presented here could help solve the "puzzling mistery" (sic, Byrne and Murray, 2002) of the northem polar cap deposits. These authors interpret the stratigraphy of those deposits as if the northern polar ice cap would be an only recent structure superposed on an extensive erg requiring a much warmer climate. The water now locked in the cap would have to be elsewhere, they argue. We suggest that when obliquity was high (i.e., in the last 5 to $9 \mathrm{Ma}$, an age compatible with our crater counting), the polar caps sublimated, there was a transient relatively dense atmosphere, and ice accumulated at low latitudes (Jakosky and Carr, 1985), for instance leeward of the high Thars is volcanoes, perhaps helped by gases exhalated by the volcanoes themselves (Hodges and Moore, 1979). As far as we know, this mechanism is the only solution for such an abrupt planetary climatic change.
Our analysis adds to this dynamic portrait in two other aspects, volcanism and tectonics. The possibility that the Tharsis Montes have been recently (or are still) active has been repeatedly evoked (Dohm et al., 2001a, 2001b; Baker et al., 2002). A basal fissural eruption of a differentiated lava is the most feasible option for a late magmatic pulse. It is the same type of activity described by Burr and McEwen (2002) at Cerberus Fossae, but the parallel can be taken a little further. The fissures at Cerberus served as vents for magma and outflows, and some faults at Arsia Mons foot, which appear at the head of the lobate terrain, could have been the source of the water now at the core of the rock glaciers.

As for the tectonics, the source of strains over the martian lithosphere, be they modern or ancient, has always been enigmatic. Some researchers (e.g., Dohm and Tanaka, 1999; Anderson and Dohm, 2000; Phillips et al., 2001) defend that all deformations on Mars are (1) very old, or (2) due to vertical (Tharsis bulge) tectonics, while other (Anderson et al., 2001; Dohm et al., 2001a, 2001b, 2002; Baker et al., 2002) propose an Amazonian or even possibly current tectonic activity. The faults affecting the aureole deposits of the Thars is Montes and the $4^{\bullet} \mathrm{N}, 130^{\circ} \mathrm{W}$ graben could in theory be due to the charge imposed on the lithosphereby the masses of the volcanic constructs (Borgia et al., 2000), but their geometry, non-radial as viewed from the center of the bulge, argues against this hypothesis. Though our structural interpretations are only tentative, the scarcity or practical absence of craters on those areas is difficult to reconcile with an ancient tectonics; nor the variety of structures seems to be typical of vertical strains. Further structural analyses, both at Tharsis and elsewhere, should be carried out to find support for this new image of a still 'alive Mars.'

\section{Conclusions}

1. The best explanation for recent glacier flow at high altitudes and low latitudes on Mars is an abrupt change in the martian obliquity, as first advanced by Laskar (1989).

2. The evidence for recent volcanism and tectonics point to a planet with remaining internal energy.

3 . The proposed ages for endogenic and exogenic activity would necessarily place Mars among the active planetary bodies, a quite interesting place for the immediate and ensuing exploration missions.

\section{Acknowledgments}

This work has benefited from several discussions with the members of the Seminario de Ciencias Planetarias (UCM) and from the careful revision of Dr. J. Dohm and an anonymous referee. 


\section{References}

Anderson, R.C., Dolun, J.M., 2000. Magmatic-tectonic evolution of Tharsis. Proc. Lunar Planet. Sci. Conf. 31. Abstract 1607.

Anderson, R.C., Dolun, J.M., Golombek, M.P., Haldemann, A.F.C., Franklin, B.J., Lias, J., Peer, B., 2001. Primary centers and secondary concentrations of tectonic activity through time in the westem hemisphere of Mars. J. Geophys. Res. 106, 20563-20585.

Anguita, F., Moreno, F., 1992. Shear-induce folding in Arsia Mons aureole: evidence for low-latitude matian glaciations. Earth Moon Planets 59, 11-22.

Anguita, F., Farelo, A.F., López, V., Mas, C., Muñoz, M.J., Márquez, A., Ruiz, J., 2001. Tharsis Dome, Mars: new evidence for NoachianHesperian thick-skin and Amazonian thin-skin tectonics. J. Geophys. Res. 106, 7577-7589.

Baker, V.R., 2001. Water and the martian landscape. Nature 412, 228-236.

Baker, V.R., Strom, R.G., Gulick, V.C., Kargel, J.S., Komatsu, G., Kale, V.S., 1991. Ancient oceans, ice sheets and the hydrological cycle on Mars. Nature 352, 589-594.

Baker, V.R., Strom, R.G., Dolın, J.M., Gulick, V.C., Kargel, J S., Komatsu, G., Ori, G.G., Rice Jr., J.W., 2000. Mars' Oceanus Borealis, ancient glaciers, and the MEGAOUTFLO hypothesis. Proc. Lunar Planet. Sci. Conf. 31, 1863. Abstract [CD-ROM].

Baker, V.R., Manuyama, S., Dohm, J.M., 2002. A theory of early plate tectonics and subsequent long-term superplume activity on Mars. Electron. Geosci. 7. http://lin springer.de/service/joumals/10069/free/ conferen/superplu.

Borgia, A., Delaney, P., Denlinger, R.P., 2000. Spreading volcanoes. Arruu Rev. Earth Plamet. Sci. 28, 539-570.

Brm, J.P., Wenzel, F., the ECORS-DEKORP Tearns, 1992. Deep crustal structure of the Rhine Graben from DEKORP-ECORS seismic reflection data: a summary. Tectonophysics 208, 139-147.

Burr, D.M., McEwen, A.S., 2002. Recent aqueous floods from the Cerberus Fossae, Mars. Geophys. Res. Lett. 29 (13), 1-4.

Byme, S., Murray, B.C., 2002. North polar stratigraphy and the paleo-erg of Mars. J. Geophys. Res. 107 (11), 1-12.

Cabrol, N.A., Grin, E.A., 2001. The evolution of lacustrine emrironments on Mars: is Mars only hydrologically dormant? Icarus 149, 291328.

Carr, M.H., 1996. Water on Mars. Oxford Univ. Press, Oxford.

Colaprete, A., Jakosky, B.M., 1998. Ice flow and rock glaciers on Mars. J. Geophys. Res. 103, 5897-5909.

Costard, F., Forget, F., Mangold, N., Peulvast, J.P., 2002. Formation of recent martian debris flows by melting of near-surface ground ice at high obliquity. Science 295, 110-113

Dolun, J.M., Tanaka, K.L., 1999. Geology of the Thanmasia region, Mars: plateau development, valley origins, and magmatic evolution. Planet. Space Sci. 47, 411-431.

Dolun, J.M., Ferris, J.C., Baker, V.R., Anderson, R.C., Hare, T.M., Strom, R.G., Barlow, N.G., Tanaka, K.L., Klemaszewski, J.E., Scott, D.H., 2001a. Ancient drainage basin of the Tharsis region, Mars: potential source for outflow channel systems and putative ocean or paleolakes. J. Geophys. Res. 106, 32943-32958

Dolun, J.M., Tamaka, K.L., Hare, T.M., 2001b. Geologic map of the Thaumasia region of Mars. US Geol. Survey Map I-2650.

Dolın, J.M., Manuyama, S., Baker, V.R., Anderson, R.C., Ferris, J., Hare, T.M., 2002. Plate tectonism on early Mars: diverse geological and geophysical evidence. Proc. Lunar Planet. Sci. Conf. 33. Abstract 1639

Fairén, A.G., Ruiz, J., Anguita, F., 2002. An origin for the linear magnetic anomalies on Mars through accretion of terrains: implications for dynamo timing. Icarus 160, 220-223.

Fishbaugh, K., Head, J.W., Pratt, S., 2000. South Polar chasmata: analysis of MOLA data and evidence for basal melting and ponding in the Prometheus Basin. Proc. Lunar Planet. Sci. Conf. 31. Abstract 1206.
Frey, H.V., 2003. Large-diameter visible and buried impact basins on Mars. linplications for age of the highlands and (buried) lowlands and tum-off of the global magnetic field. Proc. Lunar Planet. Sci. Conf. 34. Abstract 1838 .

Garvin, J.B., Sakimoto, S.E.H., Frawley, J.J., 2000. North polar region craterforms on Mars: geometric characteristics from the Mars Orbiter Laser Altimeter. Icamus 144, 329-352.

Gilınore, M.S., Phillips, E.L., 2002. Role of aquicludes in formation of martian gullies. Geology 30, 1107-1110.

Haberle, R.M., McKay, C.P., Schaefer, J., Josui, M., Cabrol, N.A., Grin, E.A., 2000. Meteorological control on the formation of paleolakes on Mars. Proc. Lunar Planet. Sci. Conf. 31, 509.

Haberle, R.M., Murphy, J.R., Schaeffer, J., 2003. Orbital change experiments with a Mars general circulation model. Icarus 161, 66-89.

Hanmann, W.K., Berman, D.C., 2000. Elysium Planitia lava flows: crater count chronology and geological implications. J. Geophys. Res. 105, 15011-15025.

Hanmann, W.K., Malin, M., McEwen, A.S., Carr, M., Soderblom, L., Thomas, P., Danielson, E., James, P., Veverka, J., 1999. Evidence for recent volcanism on Mars from crater counts. Nature 397, 586-589.

Hanmann, W.K., Anguita, J., de la Casa, M.A., Bernnan, D.C., Ryan, E.V., 2001. Martian cratering 7: the role of impact gardening. Icarus 149, $37-53$

Head, J.W., Marchant, D.R., 2003. Cold-based mountain glaciers on Mars: westem Arsia Mons. Geology 31, 641-644.

Helgason, J., 1999. Formation of Olympus Mons and the aureole escarpment problem on Mars. Geology 27, 231-234.

Hodges, C.A., Moore, H.J., 1979. The subglacial birth of Olympus Mons and its aureoles. J. Geophys. Res. 84, 8061-8074.

Hodges C.A., Moore H.J., 1994. Atlas of volcanic landforms on Mars. USGS Prof. Paper 1534. US Govt. Printing Office, Washington.

Jakosky, B.H., Camr, M.H., 1985. Possible precipitation of ice at low latitudes of Mars. Nature 315, 559-561

Jakosky, B.H., Phillips, R.J., 2001. Mars' volatile and climate history. Nature 412, 237-244

Kieffer, H.H., Zent, A.P., 1992. Quasi-periodic climate change on Mars. In: Kieffer, H.H., Jakosky, B.M., Snyder, C.W., Matthews, M.S. (Eds.), Mars. Univ. of Arizona Press, Tucson, pp. 1180-1233.

Laskar, J., 1989. A numerical experiment on the chaotic behaviour of the Solar System. Nature 338, 237-238.

Laskar, J., 1990. The chaotic motion of the Solar System. A numerical estimation of the sizes of the chaotic zones. Icamus 88, 266-291.

Laskar, J., Robutel, P, 1993. The chaotic obliquity of the planets. Nature 361, 608-612.

Laskar, J., Levrard, B., Mustard, J.F., 2002. Orbital forcing of the martian polar layered deposits. Nature 419, 375-377.

Leovy, C., 2001. Weather and climate on Mars. Nature 412, 245-249.

Lucchitta, B.K., 1981. Mars and Earth: comparison of cold climate features. Icarus 45, 264-303.

Malin, M.C., Caplinger, M.A., Davis, S.R., 2001. Observational evidence for an active sufface reservoir of solid carbon dioxide on Mars. Science 294, 2146-2148.

McKay, C.P., 1986. Exobiology and future Mars missions: the search for Mars' earliest biosphere. Adv. Space Res. 6, 269-285.

Mellon, M.T., Jakosky, B.H., 1993. Geographic variations in the thermal and diffusive stability of ground ice on Mars. J. Geophys. Res. 98, 3345-3364.

Mischna, M.A., Richardson, M.I., Wilson, R.J., McCleese, D.J., 2003. On the orbital forcing of martian water and $\mathrm{CO}_{2}$ cycles: a general circulation model study with simplified volatile schemes. J. Geophys. Res. 108.

Mustard, J.F., Cooper, C.D., Riflen, M.K., 2001. Evidence for recent climate change on Mars from the identification of youthfil near-surface ground ice. Nature 412, 411-414.

Phillips, R.J., Zuber, M.T., Solomon, S.C., Golombek, M.P., Jakosky, B.M., Banerdt, W.B., Smith, D.E., Williams, R.M.E., Hynek, B.M., Aharonson, O., Hauck, S.A., 2001. Ancient geodynamics and global scale hydrology on Mars. Nature 291, 2587-2590. 
Prodehl, C., Mueller, S., Haak, V., 1995. The European Cenozoic Rift System. In: Olsen, M. (Ed.), Continental Rifts: Evolution, structure, tectonics. In: Developments in Geotectonics, vol. 25. Elsevier, Amsterdam, pp. 133-212.

Rosendahl, B.R., 1987. Architecture of continental rifts with special reference to East Africa. Anru. Rev. Earth Planet. Sci. 15, 445-503.

Scott D.H., Zimbelman, J.R., 1995. Geologic map of Arsia Mons volcano, Mars. USGS Misc. Inv. Map I-2480.

Scott D.H., Dolın, J.H., Zimbelman, J.R., 1998. Geologic map of Pavonis Mons volcano, Mars. USGS Misc. Inv. Map I-2561.

Solomon, S.C., 18 colleagues, 2002. Insights into the earliest history of Mars: anew synthesis. Proc. Lunar Planet. Sci. Conf. 33. Abstract 1687.

Touma, J., Wisdom, J., 1993. The chaotic obliquity of Mars. Science 259, 1294-1297.
Treiman, A.H., 2003. Geologic settings of martian gullies: implications for their origins. J. Geophys. Res. 108.

Ward, W.R., Rudy, D.J., 1991. Resonant obliquity of Mars? Icarus 94, $160-164$.

Weiss, B.P., Shuster, D.L., Stewart, S.T., 2002. Temperatures on Mars from ${ }^{40} \mathrm{Ar} /{ }^{39} \mathrm{Ar}$ thermochronology of ALH84001. Earth Planet. Sci. Lett. 201, 465-472.

Wemicke, B., Burchfiel, B.C., 1982. Modes of extensional tectonics. J. Sruct. Geol. 4, 104-115.

Williams, R.S., 1978. Geomorphic processes in Iceland on Mars; a comparative appraisal from orbital images. Geol. Soc. Am. 1, 517. Abstract with progr.

Zimbelman, J.R., Edgett, K.S., 1992. The Tharsis Montes, Mars: comparison of volcanic and modified landforms. Proc. Lunar Planet. Sci. Conf. 22, 31-44. 